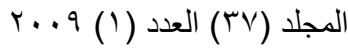
(ISSN 1815-316X)
مجلة زر اعة الر افدين
تأثير تراكيز حامض الجبرليك وعدد و فترات الرش في بعض صفات النمو لشتلات

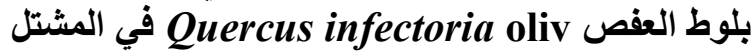 حسن نجمان محمد جياد عبد العشو كليه الزر اعة و الغابات - جامعه الموصل

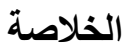

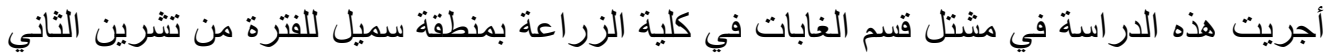

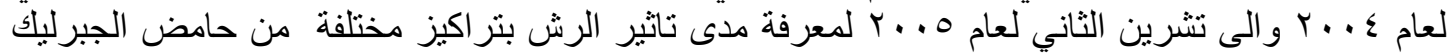

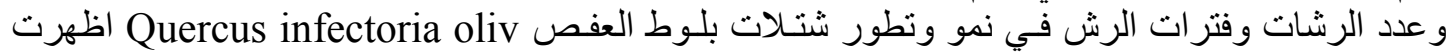

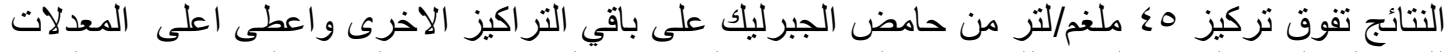

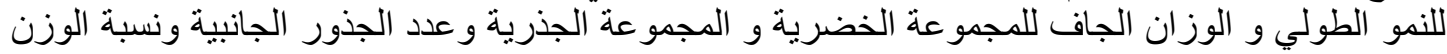

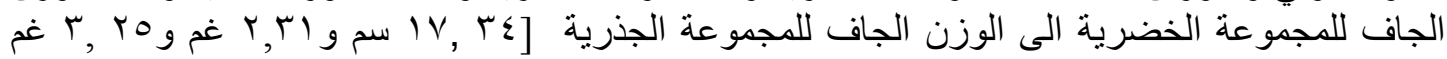

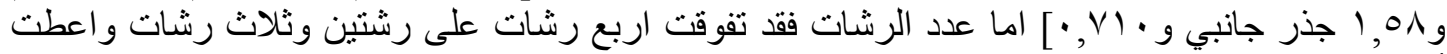

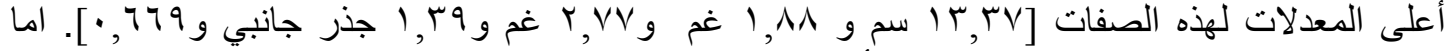

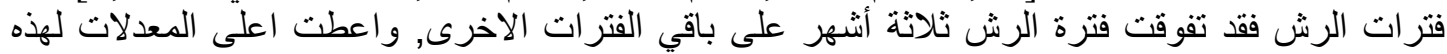

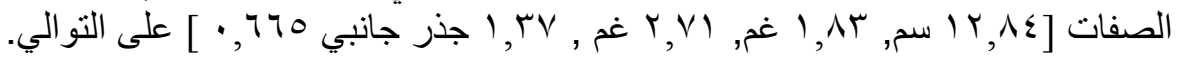

\section{المقدمة}

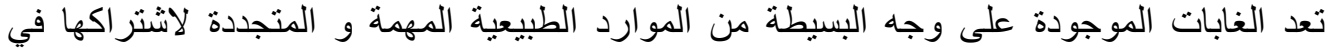

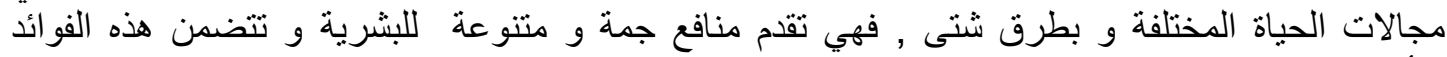

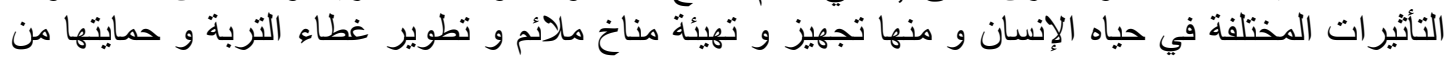

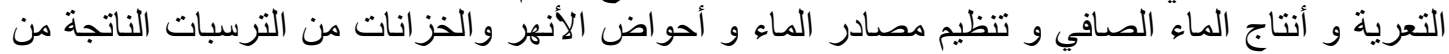

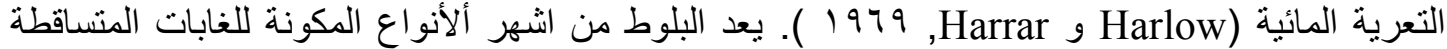

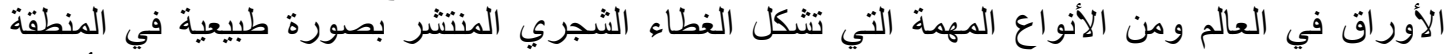

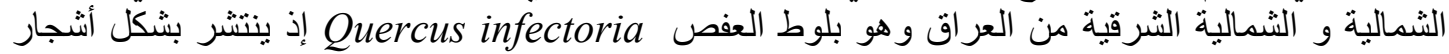

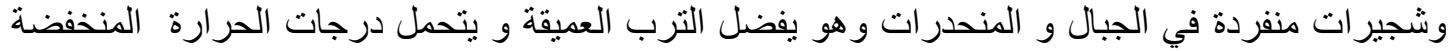

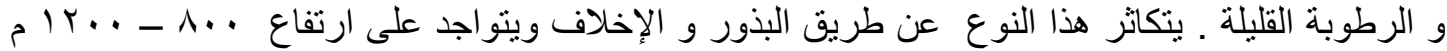

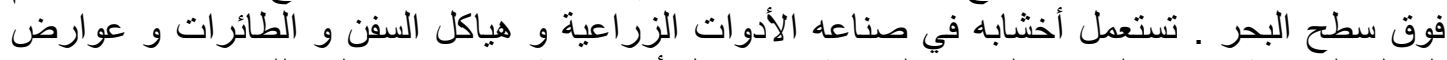

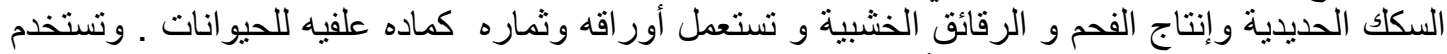

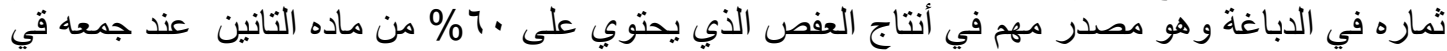

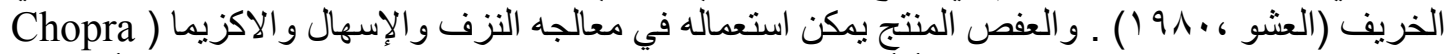

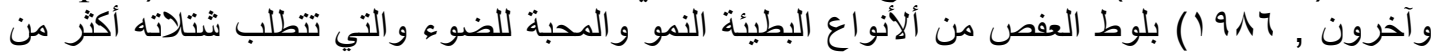

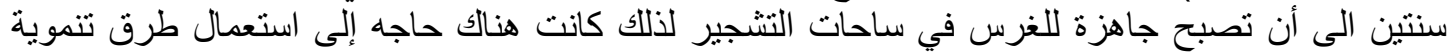

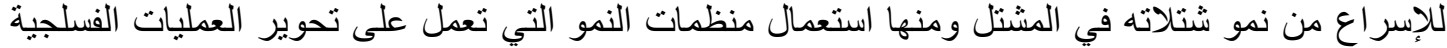

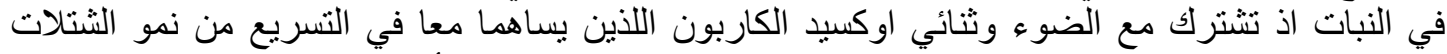

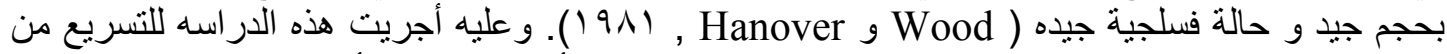

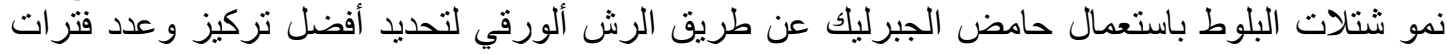

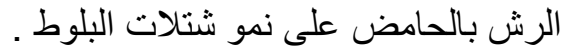

\section{مواد البحث وطرائقه}

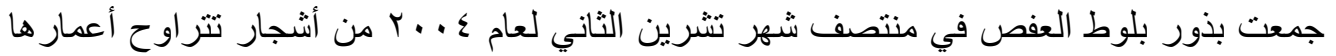

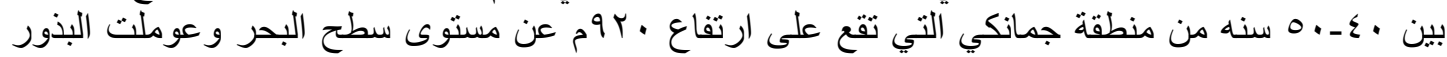

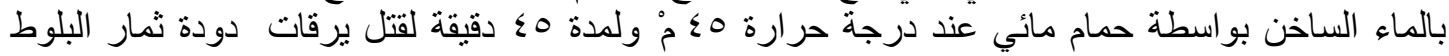

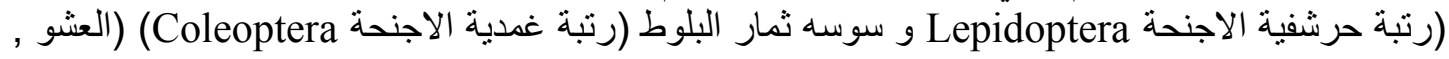




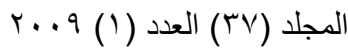
(ISSN 1815-316X)

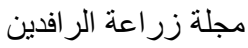

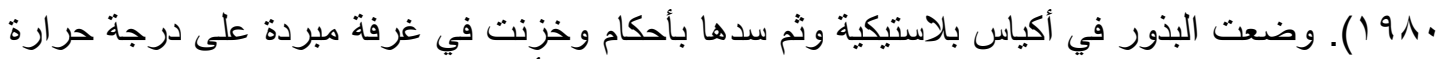

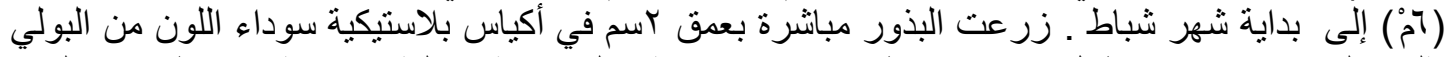

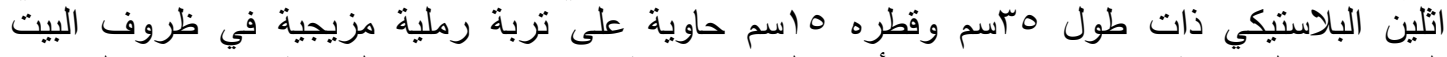

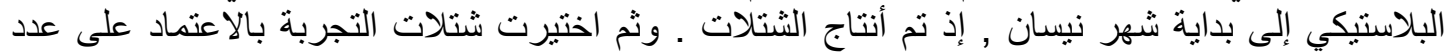

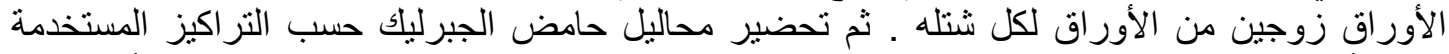

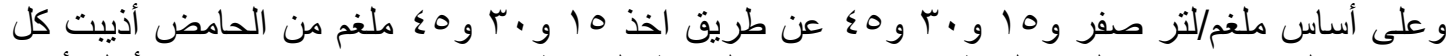

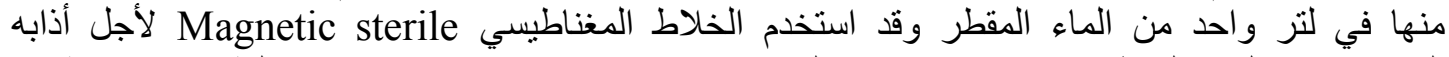

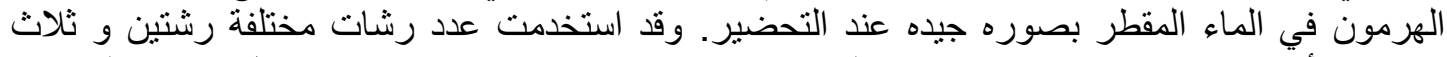

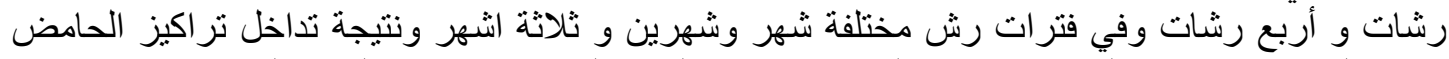

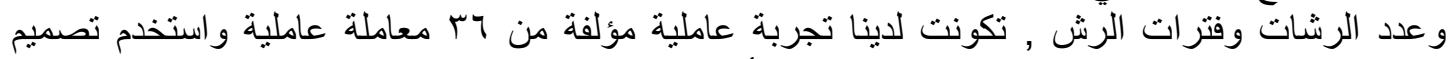

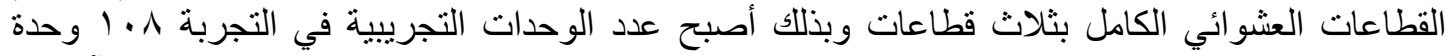

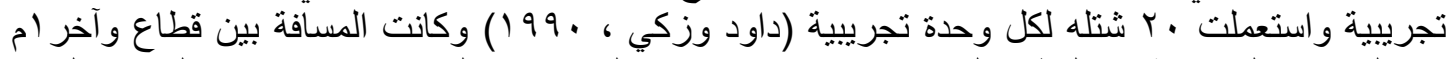

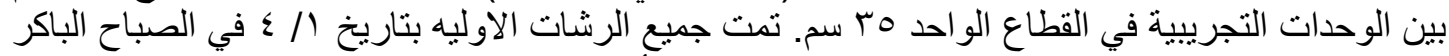

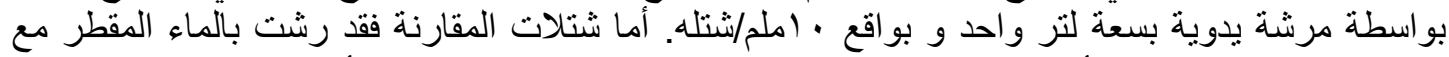

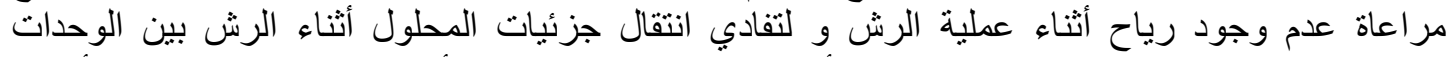

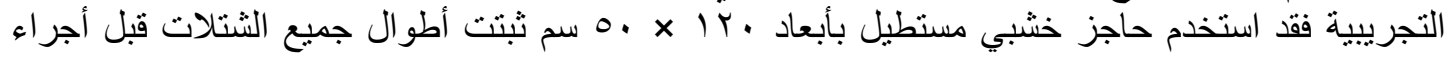

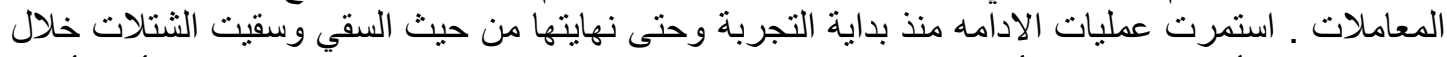

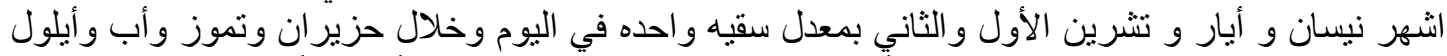

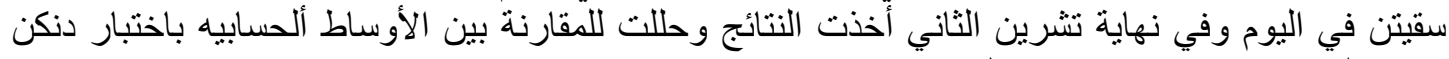
متعدد الحدود وتحت مستوى احتمال ه.

الجدول (1) : مصادر التباين و التباين التقريري وتأثثير هما في الصفات المدروسة

\begin{tabular}{|c|c|c|c|c|c|c|}
\hline \multirow{2}{*}{ عدد الجذور } & \multirow{2}{*}{ الخضبة و.جة الجى } & \multicolumn{2}{|c|}{ الوزن الجاف (غم) } & \multirow{2}{*}{ الطولي(سم) } & \multirow{2}{*}{ الحرية } & \multirow[t]{2}{*}{ مصادر التباين } \\
\hline & & الجذرية & الخضرية & & & \\
\hline., 10 & $\cdot, 1$ & $\cdot, Y \wedge$ & $\cdot 1 \ldots$ & 11,119 & $r$ & القطاعات \\
\hline$* \star \cdot, \mu q \mu$ & $* * \cdot, \cdot 1 \leq$ & **.,97r & $* *,, \vee \vee \neg$ & $* * \vee 0,970$ & ro & المعاملات \\
\hline$* * Y, 771$ & $* * ., 79$ & $* * q, 1 \vee 0$ & **V,MI. & 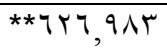 & $r$ & التر اكيز \\
\hline$* *, 0 Y 7$ & $* * \cdot, \cdot 10$ & ${ }^{* *} \cdot, V 7 V$ & **.,91. & $* *) \leq V, Y \cdot r$ & r & عدد الرشـات \\
\hline **.,rqr & $\cdot, \cdots 7$ & **., r4r & **.,0T4 & $* * 71,1 \wedge 0$ & r & فترات الرش \\
\hline${ }^{* *} \cdot, \Gamma 01$ & ** $\cdot, \cdot 7$ & ${ }^{\star *} \cdot, \leqslant \vee \wedge$ & $* * \cdot, 1 \leq 7$ & **YY, 707 & 7 & التركيز ×عدد الرشات \\
\hline *.,YTI & ${ }^{*} \cdot, \cdot \leq$ & ${ }^{*} \cdot, Y I T$ & $* \cdot, 1 \cdot 1$ & $* * 1,9,99 \leq$ & 7 & التركيز ×فترات الرش \\
\hline * $\cdot, r T$ & $\cdot, \cdots 1$ & ${ }^{*} \cdot, Y, Y$ & ${ }^{*} \cdot, 1 \cdot V$ & $0, V I r$ & $\varepsilon$ & عددالرشات ×فترات الرش \\
\hline$*, r \wedge 0$ &,$\cdot \cdots$ & $* ., 194$ & ${ }^{*} \cdot, \cdot \wedge r$ & $* * 1 \cdot, r 09$ & ir & التركيز x عدد الرشات \\
\hline$\cdot, 79$ & $\cdot, \cdots 04$ & $\cdot, \cdot \vee 1$ & $\cdot, \cdot \leq \varepsilon$ & $r, \leqslant r T$ & $V \cdot$ & الخطأ التجريبي \\
\hline
\end{tabular}

\section{النتائج و المناقثة}

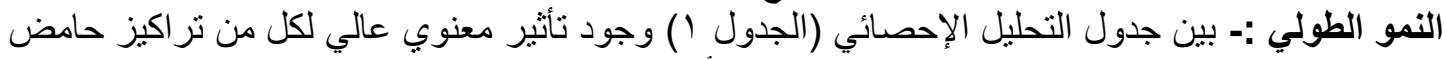

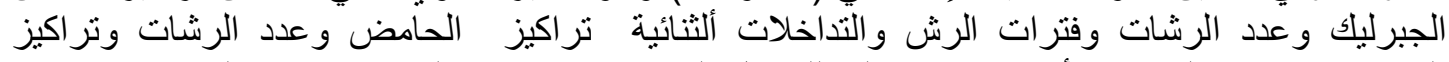

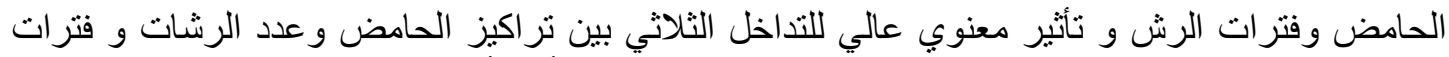

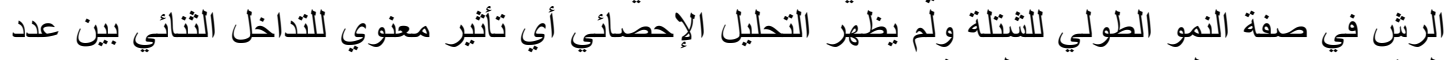

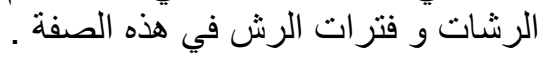

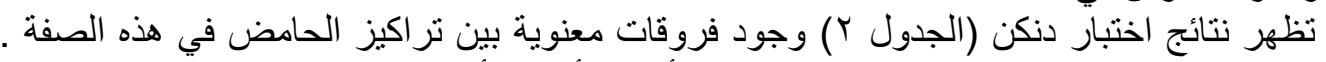

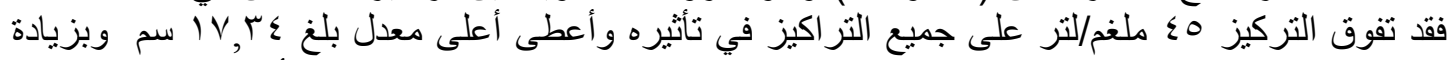

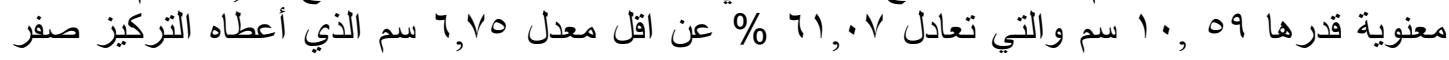




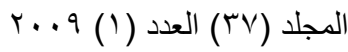
(ISSN 1815-316X)
مجلة زر اعة الر افدين

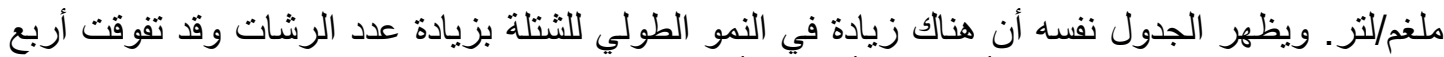

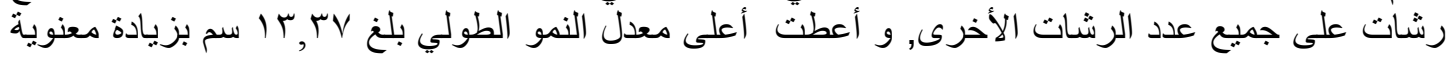

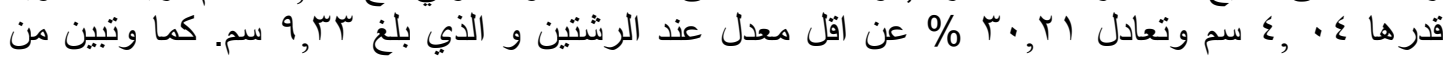

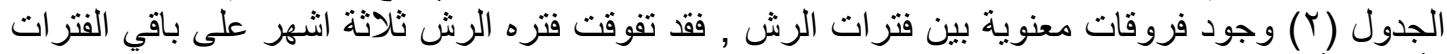

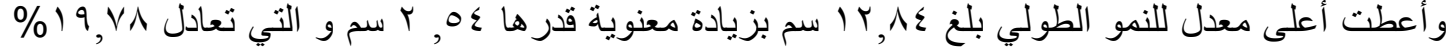

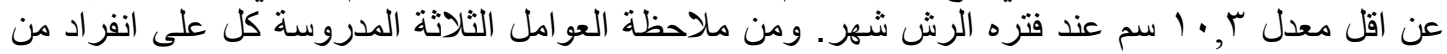

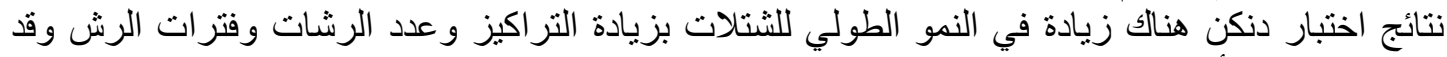

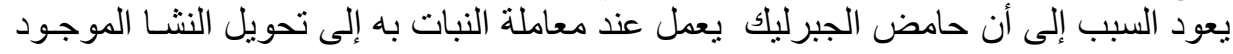

الجدول(ץ): اختبار دنكن لبيان تأثثر التراكيز الحامض وعدد الرشات وفترات الرش كل على انفراد في

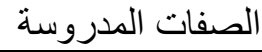

\begin{tabular}{|c|c|c|c|c|c|}
\hline \multirow{2}{*}{ عدد الجذور } & \multirow{2}{*}{ الخضبة و.جة الجى } & \multicolumn{2}{|c|}{ الوزن الجاف (غم) } & \multirow{2}{*}{$\begin{array}{l}\text { الطولي } \\
\text { (سم) } \\
\end{array}$} & \multirow{2}{*}{ 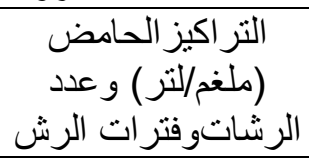 } \\
\hline & & الجذرية & الخضرية & & \\
\hline 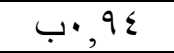 & $\rightarrow \cdot, 7 \cdot \varepsilon$ & $T^{Y}, \varepsilon$ & T & د, 1, , & صفر \\
\hline 0 & $7 \cdot, 7 \cdot 7$ & Tr, & Tr, اجד & (T, & 10 \\
\hline$i, \leqslant V$ & ب, 770 & r & 1,90 & اب, & $r$. \\
\hline \multirow[t]{2}{*}{$i 1,01$} & $i \cdot, V) \cdot$ & ir, ro & ir, ru & ilv,rs & $\leqslant 0$ \\
\hline & & & & & عدد الرشات : \\
\hline 1, 10 & 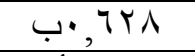 & ب, & 1, اب & 更 & رشتين \\
\hline 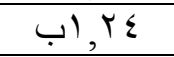 & أب & r & 10 & اب & ثناثة رشات \\
\hline \multirow[t]{2}{*}{$i, \mu_{q}$} & $1 ., 779$ & $i r, V V$ & $i, \wedge \wedge$ & IIr, & أربع رشات \\
\hline & & & & & فتر ات الرش : \\
\hline V اب اب & $\{\cdot, 7 T 1$ & بr,01 & 1,09 & اب, اب & ل شهر \\
\hline (ب & $\{\cdot, T \leqslant r$ & بr,OV & (1,71 & 1اب •, اب & شهرين \\
\hline$i$ il, rV & $1 ., 770$ & $i r, v i$ & أi, & 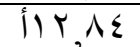 & ثلاثة أشهر \\
\hline
\end{tabular}

الأرقام التي تحمل الحروف نفسها في الصف العمودي الواحد لا تختلف معنويا فيما بينها عند مستوى احتمال ه•,. حسب

في خلايا الساق إلى سكريات ذائبة عن طريق تحليق أنزيم الالفا ـ اميليز الذي يستغل في استطالة السلاميات

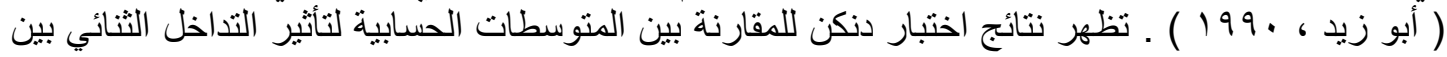

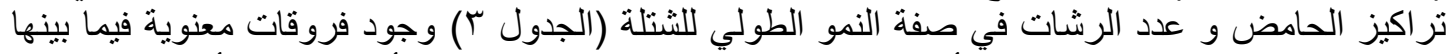

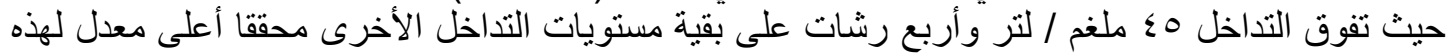

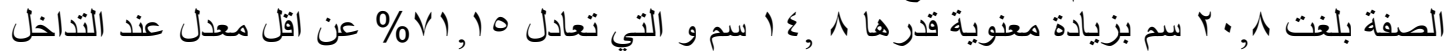

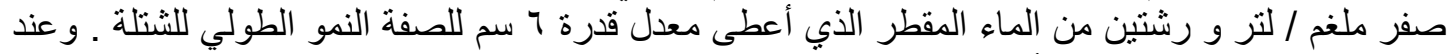

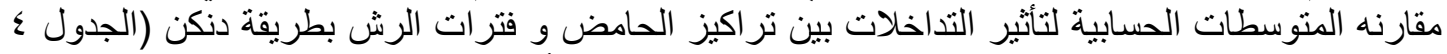

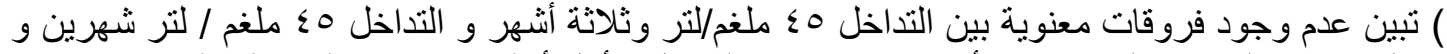

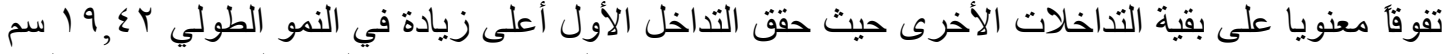

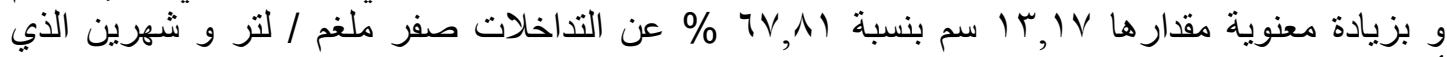

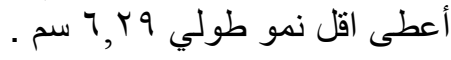

\begin{tabular}{|c|c|c|c|c|c|}
\hline \multirow{2}{*}{ عدد الجذور } & \multirow{2}{*}{ الخضبة ولجية الجى } & \multicolumn{2}{|c|}{ الوزن الجاف (غم) } & \multirow{2}{*}{ النمو الطولي } & \multirow{2}{*}{ ملغنيز التر × عدد } \\
\hline & & الجذرية & الخضرية & & \\
\hline •دهـ $9 V$ & هـ & $د, 1$ & II & 97 & صفر رشتين \\
\hline
\end{tabular}




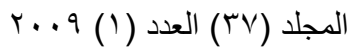
(ISSN 1815-316X)
مجلة زر اعة الر افدين

\begin{tabular}{|c|c|c|c|c|c|}
\hline هـ, & $\Delta ., 0 \wedge 9$ & $2, \cdot 0$ & I I, & هـ V,IY & صفر ثلاث رشات \\
\hline r', اج هـ & 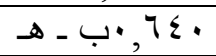 & $31,9 V$ & IT, I & Sـ V, N & صفر أربع رشات \\
\hline هـ & - 'ד TY TY & 21,99 & נו & هـ & 10 رشتين \\
\hline هץ, اب ج & $\Delta \cdot .09 Y$ & & I, r & N ג נهـ & 1 نثلاثة رشات \\
\hline$\Delta \cdot, 9 r$ & . . . & O & $21, \leqslant 1$ & 9 & 1 أربع رشات \\
\hline rاب د & 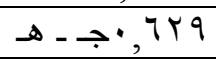 & II, & (ج) & $د \cdot, \leqslant \wedge$ & • r رشتين \\
\hline ب & - أ - TVq & Y, V & (ج), 1 & جIr,OV & • ب ثلاث رشات \\
\hline $11, \mathrm{VV}$ & - - أ & IT,rr & 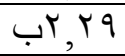 & 17,07 ب & • r أربع رشات \\
\hline r & ב _ • & $i r, 19$ & ع & T, & 0 ؛ رشتنين \\
\hline أ & م. & ir, 10 & r & (اب, & 0ـ ثلاث رشات \\
\hline i), $\wedge \varepsilon$ & i., vo. & $|r, \varepsilon|$ & $i r, o v$ & $i r \cdot$, & 0 أربع رشات \\
\hline
\end{tabular}

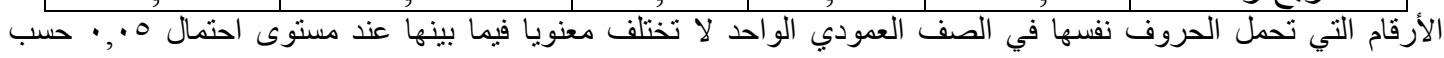

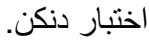

أما التداخل بين عدد الرشات و فترات الرش فقد أظهرت نتائج اختبار دنكن (الجدوله) وجود

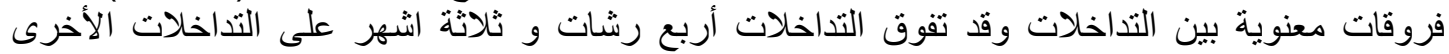

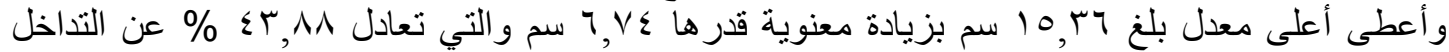

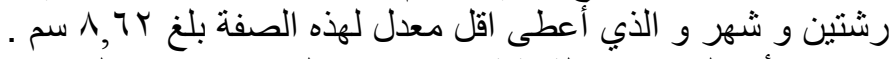

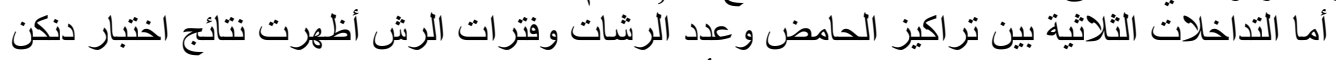

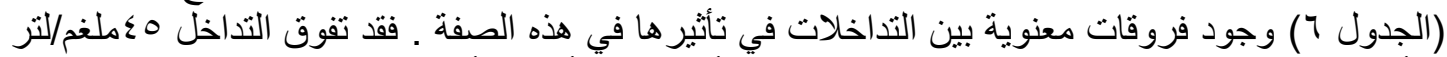

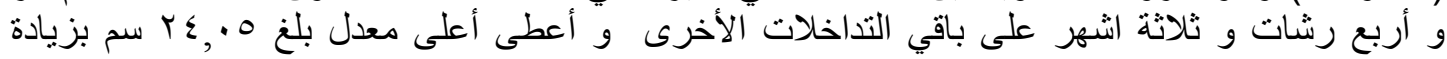

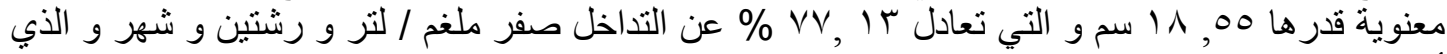

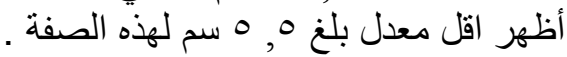
الوزن الجاف للمجموعة الخضرية غم : بين التحليل الإحصائي ( الجدول ( ) وجود تأثنير معنوي عالي لكل

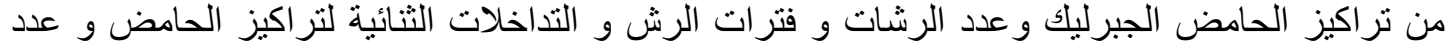

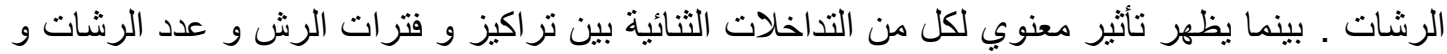

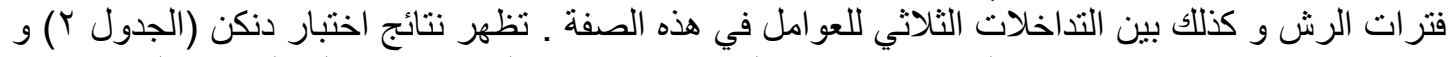

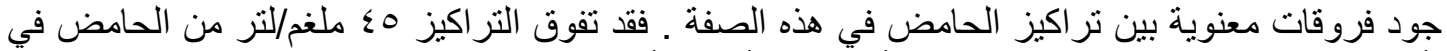

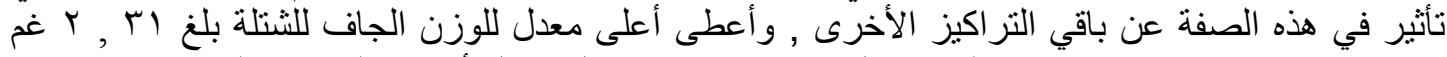

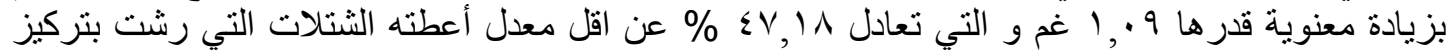

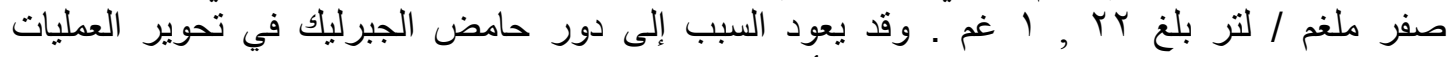

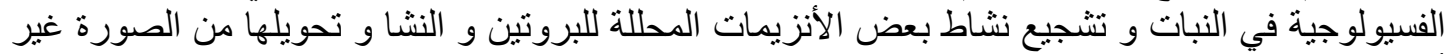

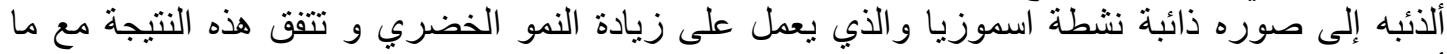

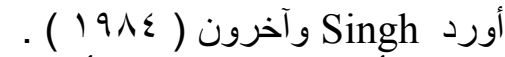

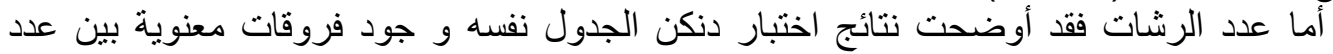

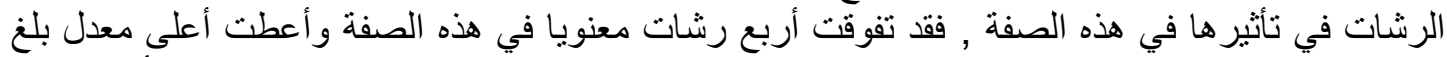

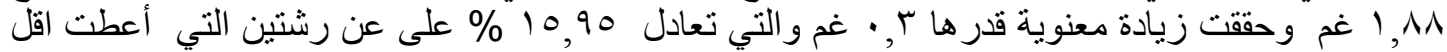
معدل بلغ 1,01 غم و هذه النتيجة تتفق مع ما أورده

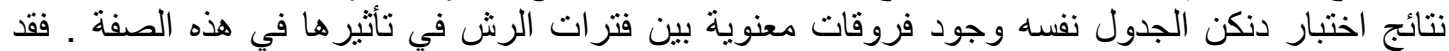

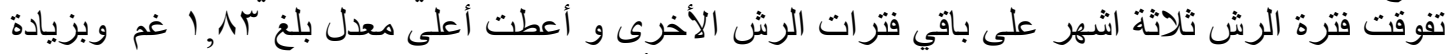

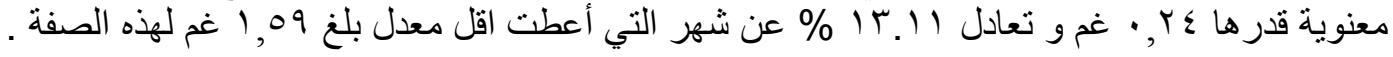

الجدول (ع) : نأثير تداخلات تر اكيز الحامض و فترات الرش في الصفات المدروسة

\begin{tabular}{|c|c|c|c|c|c|}
\hline \multirow{2}{*}{ عدد الجذور } & \multirow{2}{*}{ الخضبة و.جة الجى } & \multicolumn{2}{|c|}{ الوزن الجاف (غم) للمجم } & \multirow{2}{*}{ النمو الطولي } & \multirow{2}{*}{ (ملغم/لتر )وفتر ات } \\
\hline & & الجذرية & الخضرية & & \\
\hline
\end{tabular}




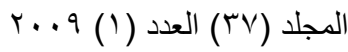
(ISSN 1815-316X)
مجلة زر اعة الر افدين

\begin{tabular}{|c|c|c|c|c|c|}
\hline د.,99 & וז7, •جב & 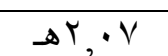 & Oץ, וهـ و & & صفر شهر \\
\hline$د \cdot, \wedge 1$ & $د \cdot, 0 V \leqslant$ & 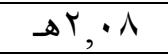 & $9, r$ & 97,19 & صفر شهرين \\
\hline اجـد & هץT, •ب د & اهـ & & g-دV, & صفر ثثلاثة أشثهر \\
\hline د • •,97 & $د \cdot 7 \cdot 7$ & Ar, 0 & ع & 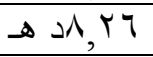 & 10 شهر \\
\hline T, IV & $3 ., 090$ & Tו, Tגני & (هـ & g-دV,Vr & 1 شهرين \\
\hline ', اج د & VוT, •ب د & נY & $\$ 1,57$ & 29 & 1 ثناثة أشهر \\
\hline${ }^{\prime}, r$ & סץT, •ب د & $\rightarrow Y, \wedge I$ & 21,10 & جإ, & r شهر ش ش \\
\hline اب & - - أ - TV7 & ج & ج, $9 V$ & ج|Y,01 & • ب شهرين \\
\hline $11, \times 7$ & & ד. & ع , , & اب & •ب ثناثة أشهر \\
\hline أب0 & 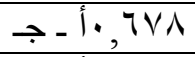 & سب & س & (ب, & 0 \\
\hline 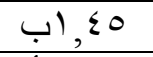 & - - أ & VIVاب & r & $\| \mathrm{l}, \wedge$ & 0 ـ شهرين \\
\hline$i, V T$ & $\{\cdot, V Y T$ & Ir, $\leqslant 0$ & $i r, 01$ & $i 19, \varepsilon r$ & 0ـ ثلاثة أثشهر \\
\hline
\end{tabular}

اختبار دنكن.

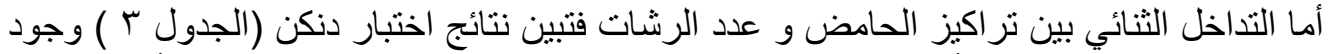

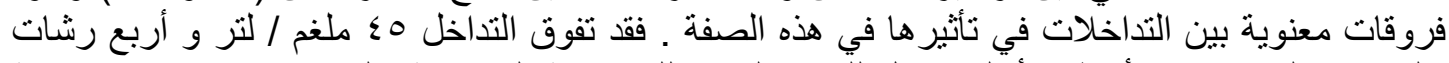

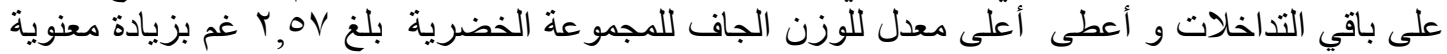

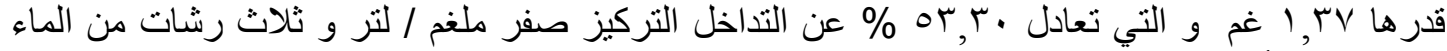

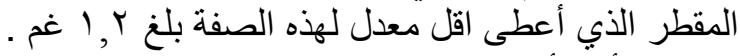

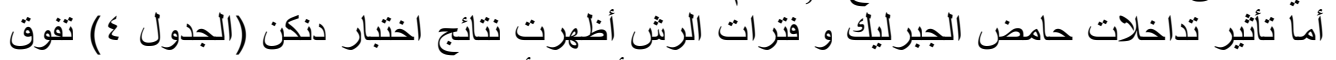

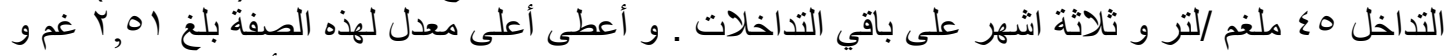

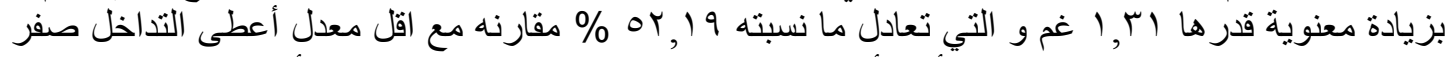

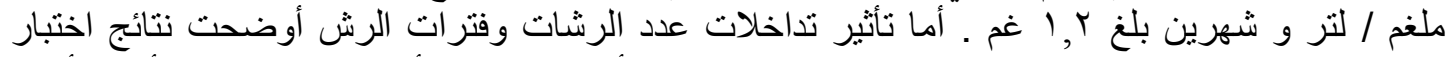

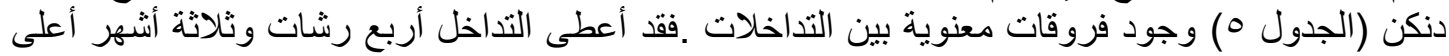

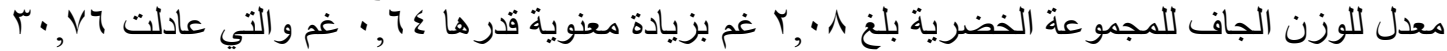

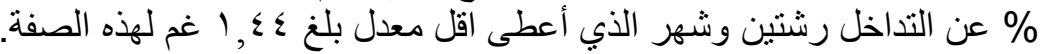

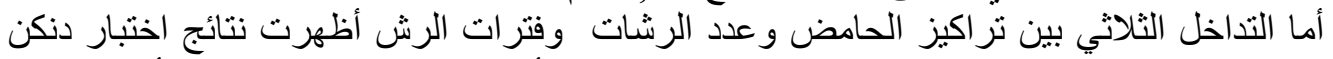

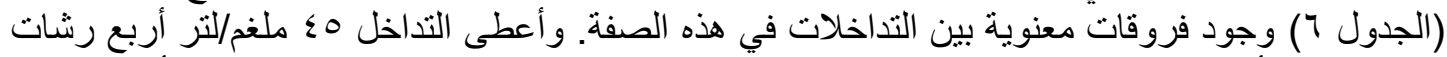

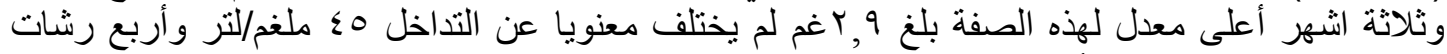

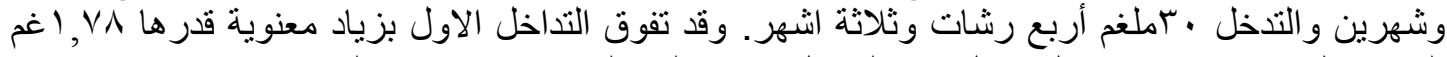

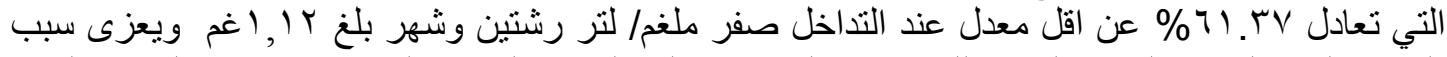

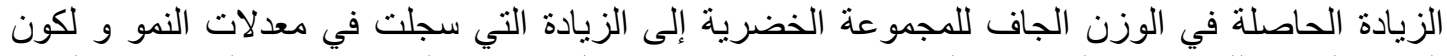

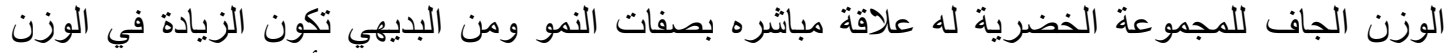

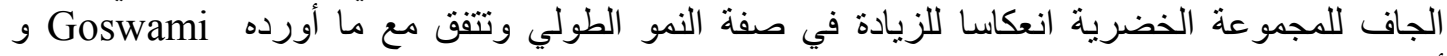

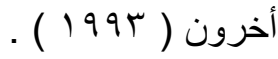

الجدول (0) : نأثير تداخلات عدد الرشات و فترات الرش في الصفات المدروسة

\begin{tabular}{|c|c|c|c|c|c|}
\hline \multirow{2}{*}{ عدد الجذور } & \multirow{2}{*}{ الخضبة و.جة الجذية } & \multicolumn{2}{|c|}{ اللازن الجاف (غم) } & \multirow{2}{*}{ النمو الطولي } & \multirow{2}{*}{ وفتر ات الرشات } \\
\hline & & الجذرية & الخضرية & & \\
\hline 71,9 & $1 \cdot, 0 \wedge \varepsilon$ & $T_{Y, \Sigma T}$ & $1, \leq \leq$ & 1 גד & رشتين شهر \\
\hline ع ا, اب ج & $\{\cdot, 7 Y \leq$ & $\rightarrow r, \leqslant q$ & I I, OV & $\rightarrow 9, \leqslant \varepsilon$ & رشتين شهرين \\
\hline اب, اب ج & $\{., 7 \vee 0$ & ك & اب & 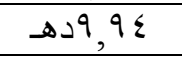 & رشتين، T أشهر \\
\hline لו, اب ج & $\{\cdot, 7 \leq \varepsilon$ & $\rightarrow r, O r$ & ج, $7 \leq$ & • ادهـ & " رشات ، شهر \\
\hline
\end{tabular}




\begin{tabular}{|c|c|c|c|c|c|}
\hline Vا, اب ج & $\{\cdot, T \leq Y$ & $\rightarrow Y, \leqslant V$ & rا, اجד د & آ, الجـد & r رشات ،شهرين \\
\hline أ ب & $\{\cdot, 7 \varepsilon$. & r & & (ب, & ب رشات، بأشهر \\
\hline آץ, اب جـ & I.,77 & ج & لر اب جـ & ג & ع رشات ، شهر \\
\hline צr, أ ب & $1 ., 77 Y$ & 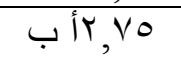 & اب , اب & 9q, זוب ج & ك رشات،شهرين \\
\hline $11,0 \leq$ & $i \cdot, 7 \wedge 1$ & ir, qV & $i r, \cdot 1$ & $110, r 4$ & ع رشات، سأشهر \\
\hline
\end{tabular}

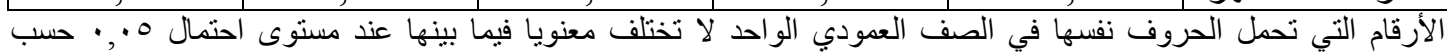

الجدول(ך): اختبار دنكن لبيان تأثير تداخلات نراكيز الحامض عدد الرشات وفترات الرش في الصفات

\begin{tabular}{|c|c|c|c|c|c|}
\hline \multirow{2}{*}{ عدد الجذور } & \multirow{2}{*}{ الخضرية الجى الج } & \multicolumn{2}{|c|}{ الوزن الجاف عمة للمجم } & \multirow{2}{*}{$\begin{array}{c}\text { النمو الطولي } \\
\text { (سم) }\end{array}$} & \multirow{2}{*}{ الرشات ومغن/لتزر) او عدد الحامض الرش الرش } \\
\hline & & الجذرية & الخضرية & & \\
\hline ن- ح- ن ن & $\{\cdot, \leqslant \wedge \uparrow$ & س & J1, & ن & صفر رشنتين شهر \\
\hline 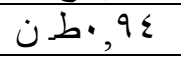 & $1 \cdot, 7 \cdot 7$ & ف & 1, & ن & صفر رشتين شهرين \\
\hline & $i \cdot, 701$ & ف ع & J & ن & صفر رشتين، أشهر \\
\hline ن., & $i \cdot, 0 \wedge r$ & س & ل & ن - b, & صفر ، آرشات شهر \\
\hline$\dot{1} \cdot, 70$ & i.,os. & S & J1,19 & ن 0 م 9 & صفر، ب رشات،شهرين \\
\hline & $i \cdot, 7 \leq \leq$ & س & 1,111 & ج ج,^^ & صفر، آرشات، rاشهر \\
\hline 1, & $i \cdot, \vee V \vee$ & ف ف 1, V9 & ג ו, ו ل & كن V & صفر ، گرشات، شهر \\
\hline 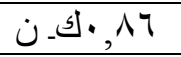 & i.,ovo & ـ ن & 51,10 & 7,90 ل-ن & صفر ، كرشات، شهرين \\
\hline 1, 1, 17 & I.,ov & ع & rي_إ_ل & צr, עي نن & صفر ، ؛ رشات، باشهر \\
\hline & i. & 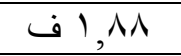 & 51,19 & & 10 رشتين شهر \\
\hline & $i \cdot, 0 \wedge r$ & $\dot{\theta} p^{r}, \cdot 1$ & J1,17 & ن ك & مارشتين وشهرين \\
\hline & $1 \cdot, 777$ & & ـ & ن & 0 ارشتين ،T أنشهر \\
\hline - هـ & $i \cdot, 71 r$ & & سז, ו ك J & $\dot{u} \tau^{\wedge}, 1$. & 10 ثلاثة رشات شهر \\
\hline (ج) & $i, 0 \wedge 7$ & 97, اسف & 4,10 & a- ح $\tau^{q}, \mu r$ & ه اثلاثة رشات شهرين \\
\hline & $i \cdot, 0 \vee \wedge$ & س & rي ـإلـ & $\dot{ن}-\tau^{\wedge}, \vee \wedge$ & م اثثلاثةرشات ثلاثة|أنشهر \\
\hline ن & i.,oVr & & $J 1, Y_{1}$ & b. & 10، رشات شهر \\
\hline (أو-1, & $i \cdot, 7) \wedge$ & $\varepsilon-b r, \Sigma l$ & 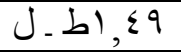 & & 0 1 ، ـ رشات شهرين \\
\hline ن., & $i \cdot, 7 \cdot 1$ & a- $\tau^{r, o r}$ & J. & $r-\tau^{q, r}$ & 10، 1ـ رشات ثلاثة|أشهر \\
\hline 9 & $i, 09 r$ & $ن-ح r, 0$ & 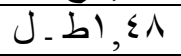 & 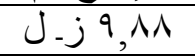 & • r ،رشتين شهر \\
\hline ن & $1 \cdot, 747$ & S_, Y, TV & S j j & 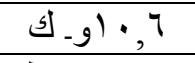 & • بر،شتين ،شهرين \\
\hline 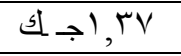 & $i \cdot, 701$ & r-ب, r, & $j \rightarrow 1,90$ & bوl.,91 & • برشتين ،T أشهر \\
\hline 0 1,19 & $i \cdot, V \cdot r$ & س & 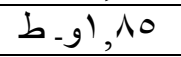 & $2-9), r q$ & • r r r رشات شهر \\
\hline & $i \cdot, 710$ & ( & $j \rightarrow 1,9 \varepsilon$ & (9.,90 & • r ، ب رشات، شهرين \\
\hline أج & $i \cdot, 7 \leqslant \Lambda$ & 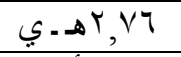 & ي, ا و - ي & 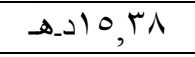 & • ب ، rرشات، ب أشهر \\
\hline$b+1, \leqslant 0$ & $i \cdot, 0 \wedge 1$ & ـ ـ أد & $\tau-81,9 r$ & (هـ, & • " ،؛ رشات شهر \\
\hline 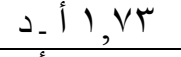 & $i \cdot, v \cdot \Lambda$ & س r, זب_هـ & 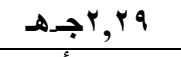 & 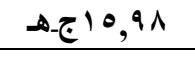 & • ب ، ع رشات شهرين \\
\hline$|Y,| \varepsilon$ & $i \cdot, \vee \vee 1$ & & r T أ ب & بr,NI & 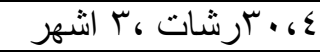 \\
\hline اجـ & $1 \cdot, 7 Y 7$ & & $j \ldots .2,91$ & $j \rightarrow \mid r, \varepsilon$ & 0؛ رشتين شهر \\
\hline سז, اجـ ل & I., $7 \mathrm{~V} \cdot$ & هر, זب_هـ & $9 \rightarrow r, 1 \wedge$ & 1 1 (هـ & 0؛رشتين وشهرين \\
\hline & $i \cdot, \vee 19$ & & $\rightarrow \rightarrow Y, Y \wedge$ & $j \rightarrow \mid r$ & 0؛، رشتين، باشهر \\
\hline ح & $i \cdot, 7 V V$ & س & g. د, I & $j \mid>1 Y, q 1$ & ك؛ ، ب رشات شهر \\
\hline 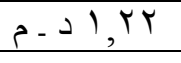 & $i \cdot, v \circ \wedge$ & $b \rightarrow r, q$ & - - & 19,19 اب-ج & 0؛، برشات شهرين \\
\hline
\end{tabular}




\begin{tabular}{|c|c|c|c|c|c|}
\hline VT, ו أهـ & $\{\cdot, 7 \wedge \wedge$ & س & צו, זب-د & ب r.,91 & 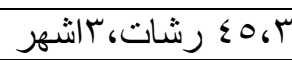 \\
\hline أج, 11, & $i \cdot, V T r$ & (r, & هـ Y, YV & 11), & 0؛ ، ،ـرشات، شُهر \\
\hline أج, أج & $i \cdot, v \leq \lambda$ & 1أج, & 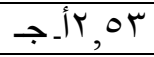 & ب r., ro & ؛ ، ، كرشات شهرين \\
\hline 1,97 أب & $i \cdot, \vee V \mid$ & $i r, v \uparrow$ & i r, $q$ & $i r \varepsilon, 0$ & ؛ ، ، كرشات، ساشهر \\
\hline
\end{tabular}

الأرقام التي تحمل الحروف نفسها في الصف العمودي الواحد لا تختلف معنويا فيما بينها عند مستوى احتمال ه•,

الوزن الجافة للمجموعة الجذرية : يظهر تحليل التباين (الجدول ال) وجود تأثير معنوي عالي لكل من تركيز

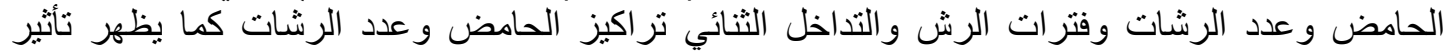

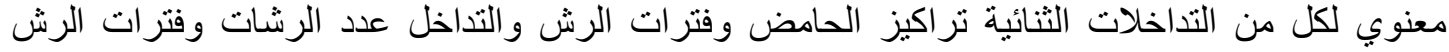

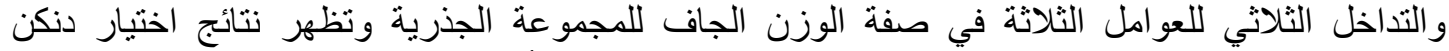

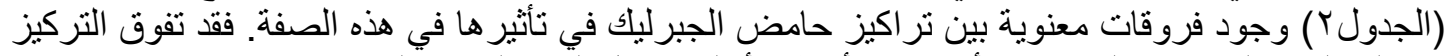

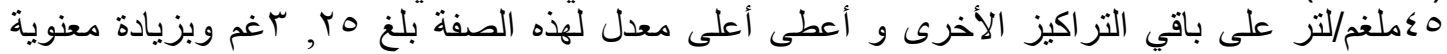

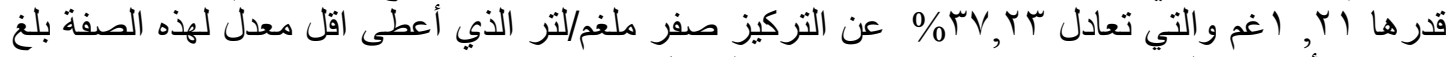

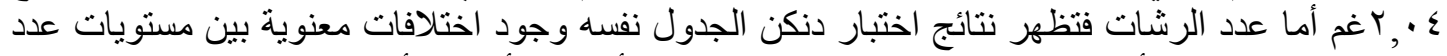

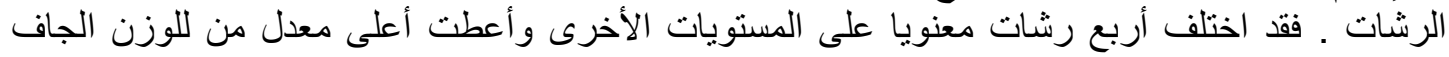

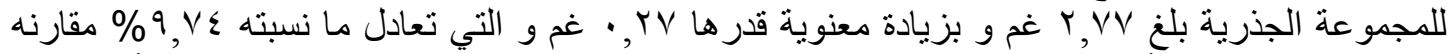

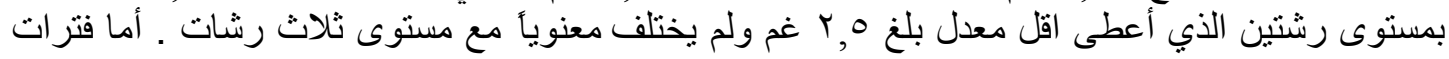

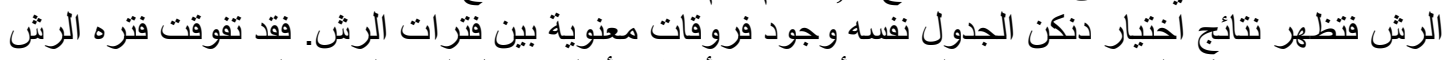

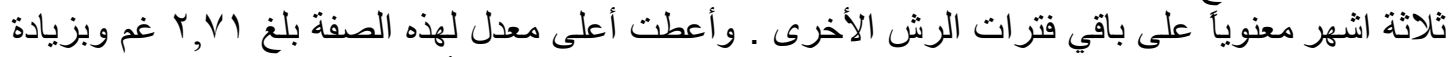

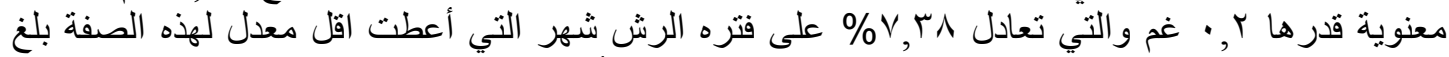

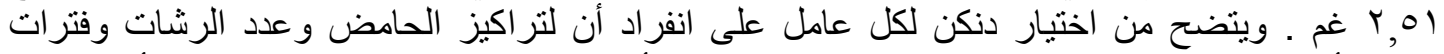

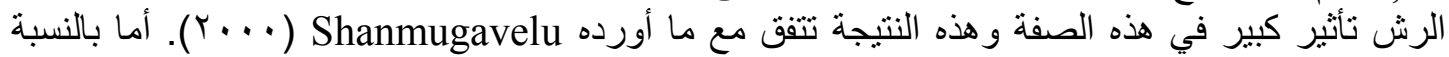

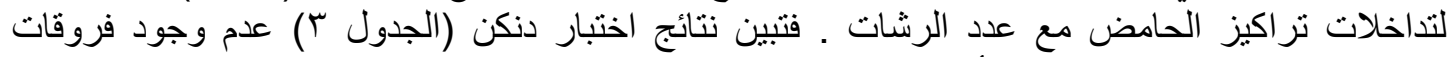

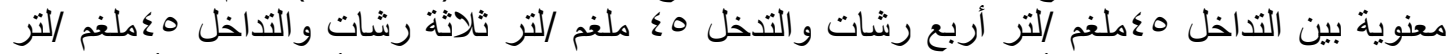

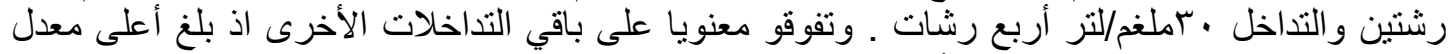

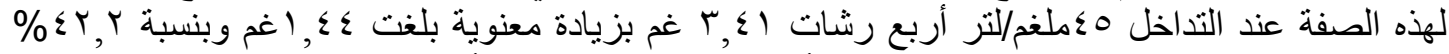

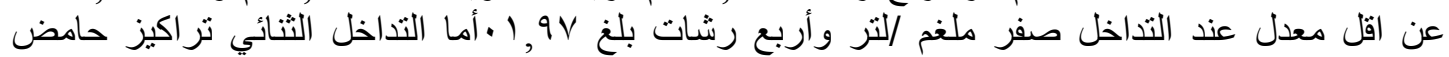

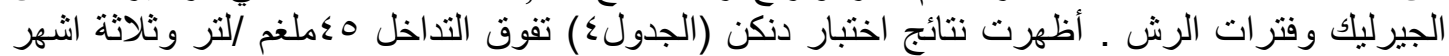

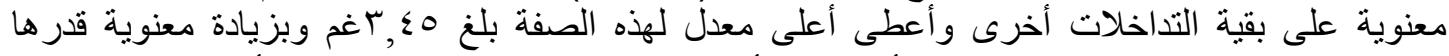

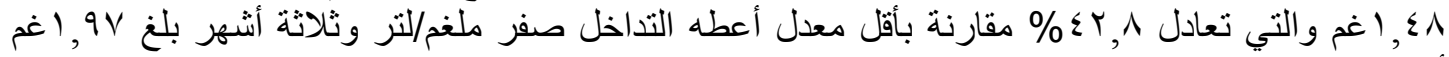

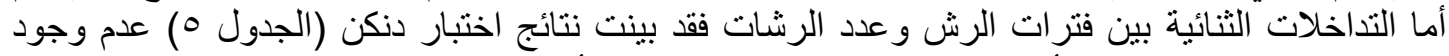

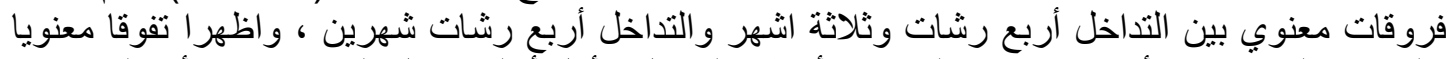

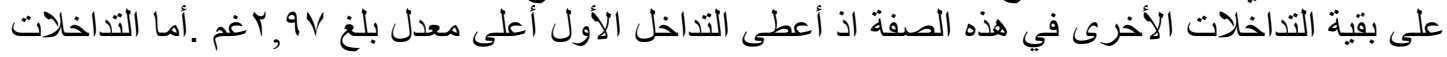

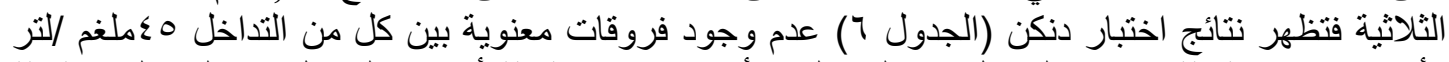

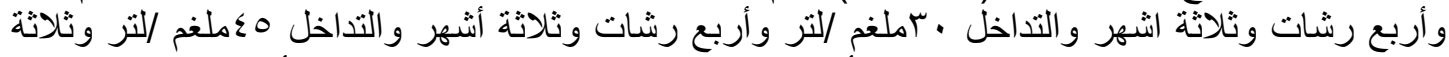

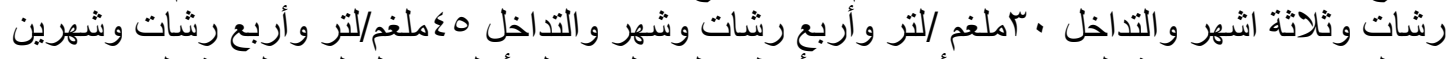

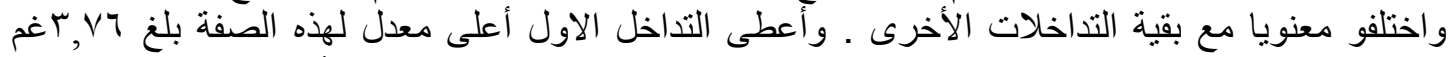

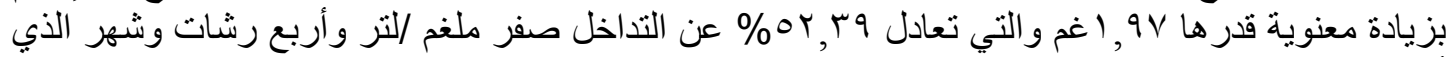

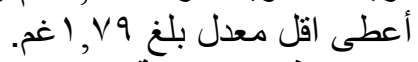

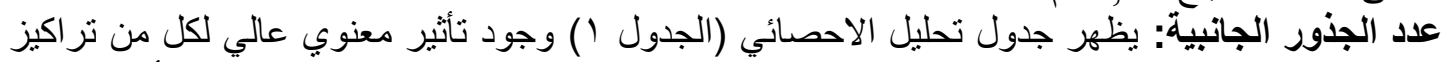

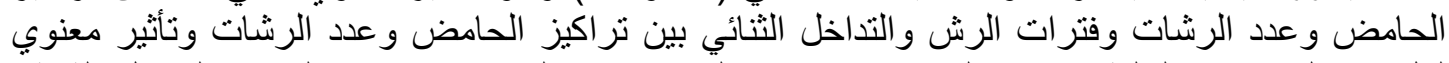

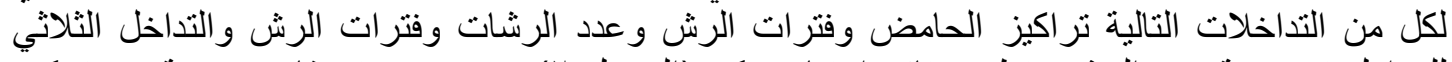

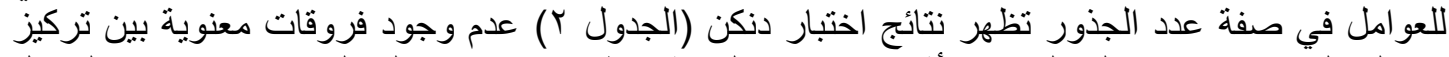

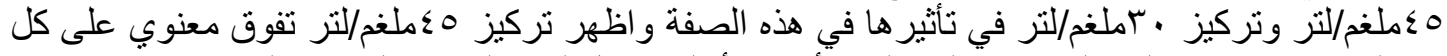

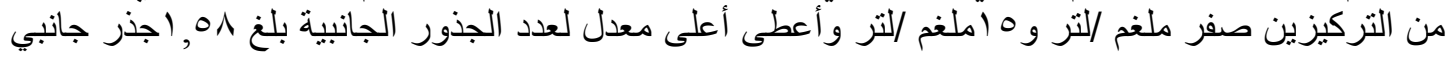




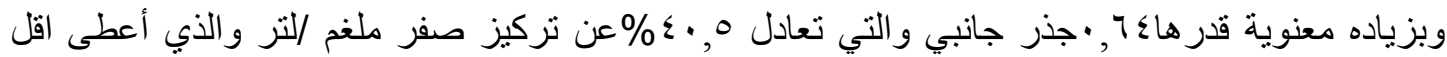

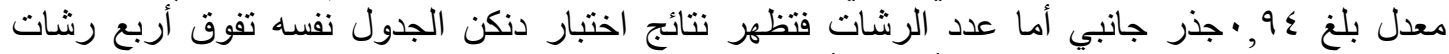

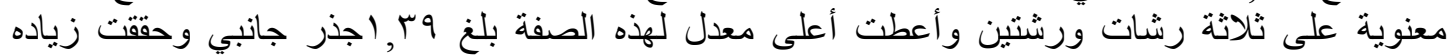

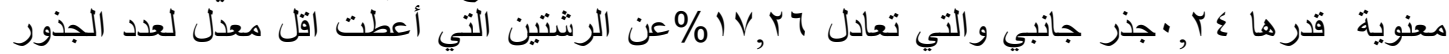

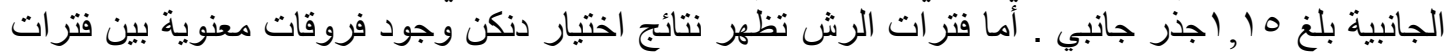

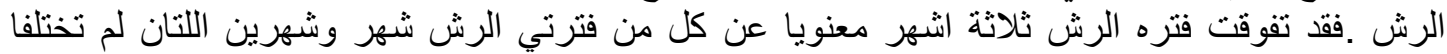

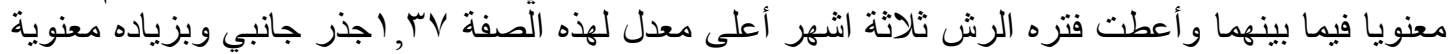

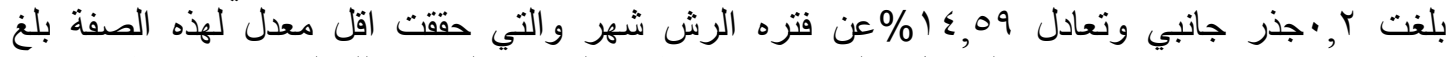

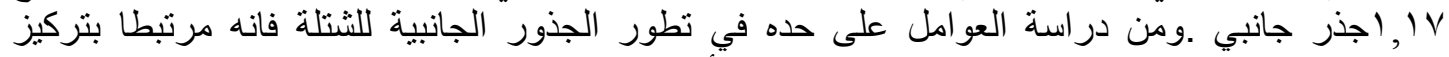

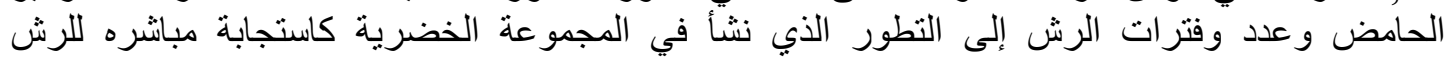

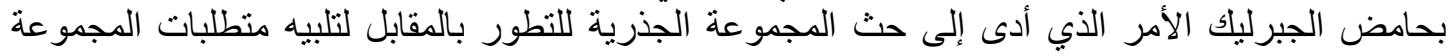

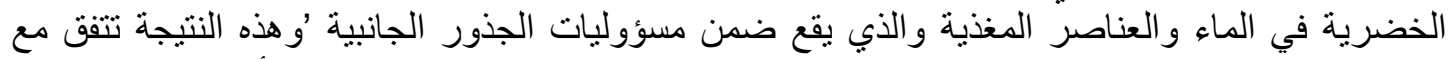

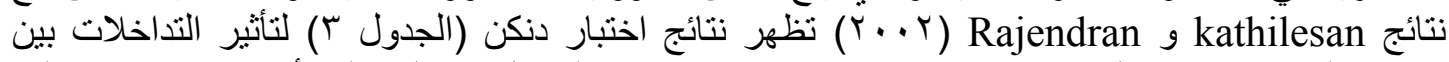

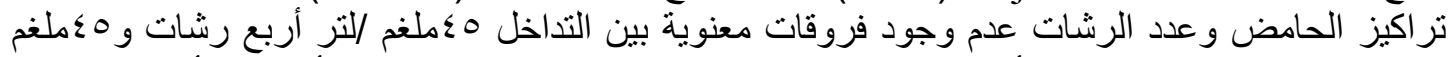

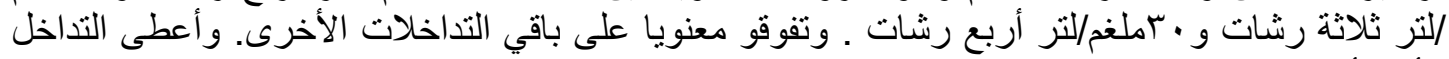

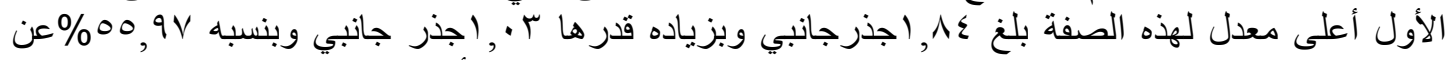

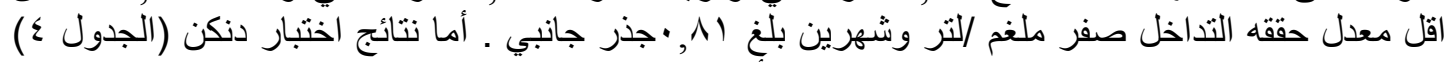

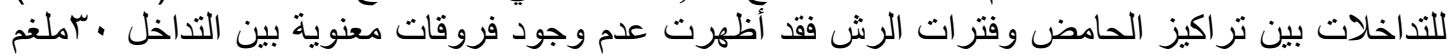

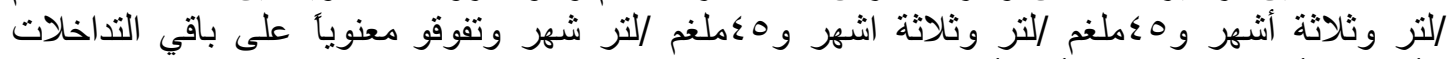

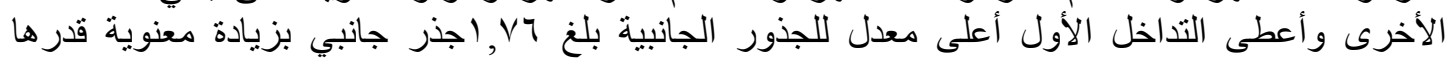

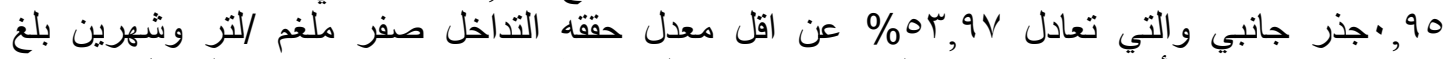

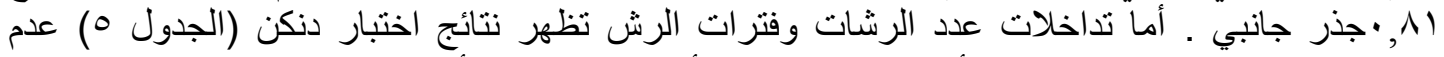

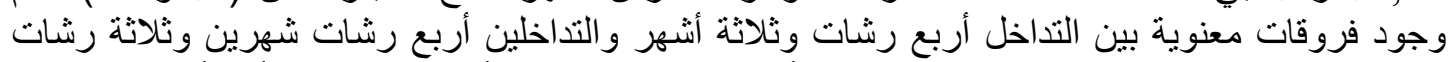

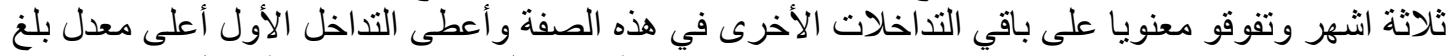

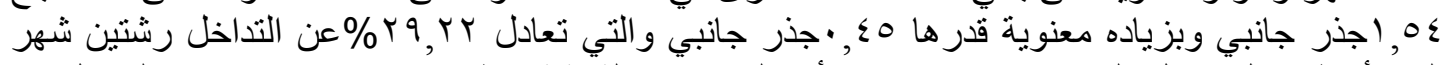

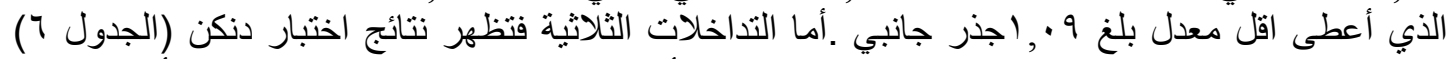

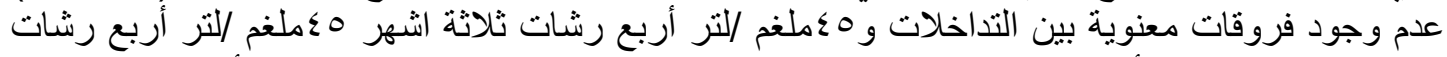

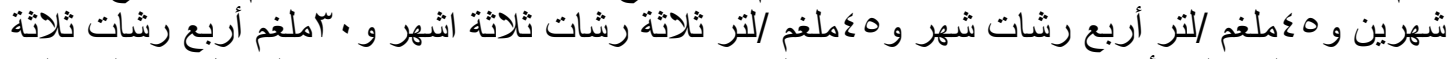

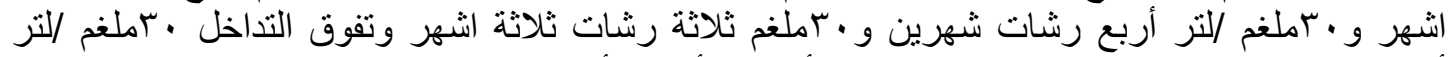

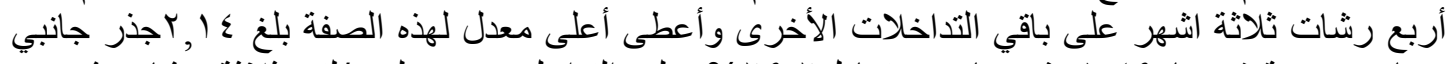

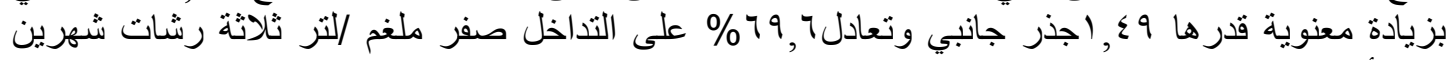

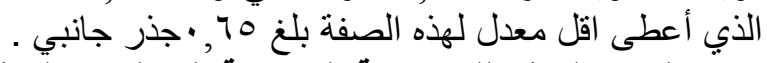

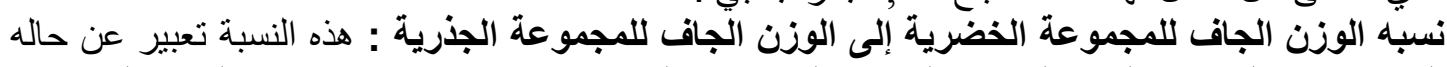

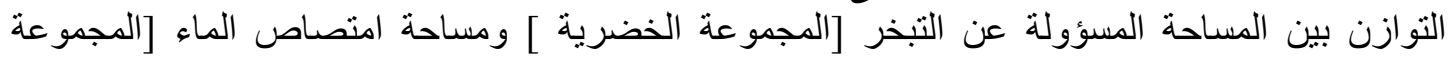

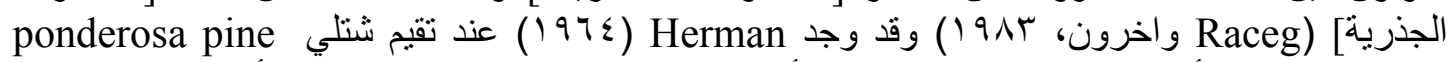

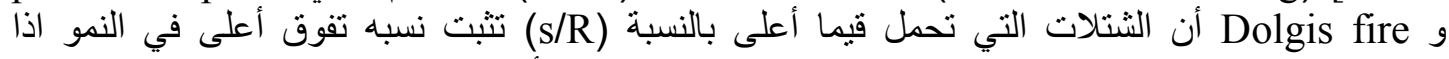

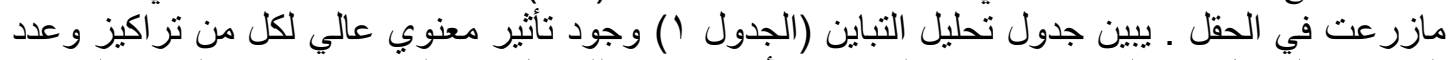

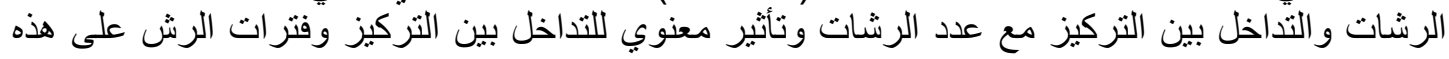

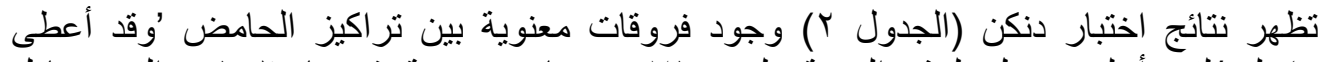

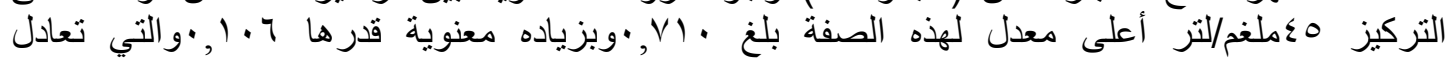

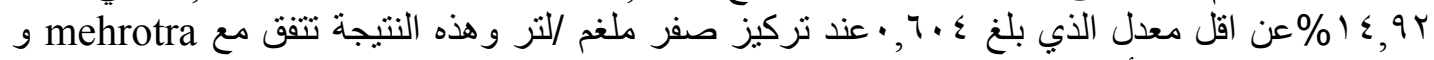

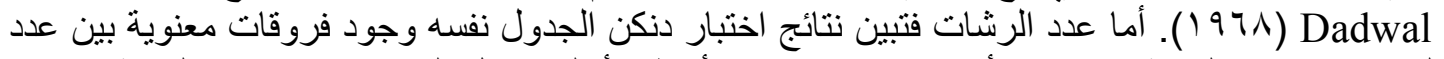

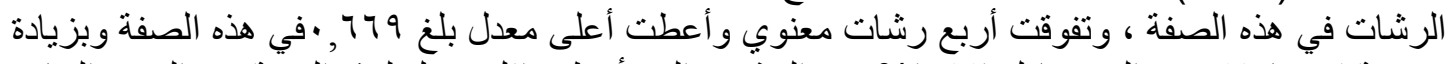

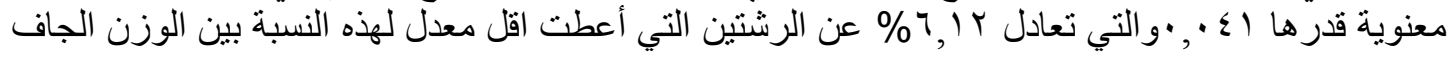

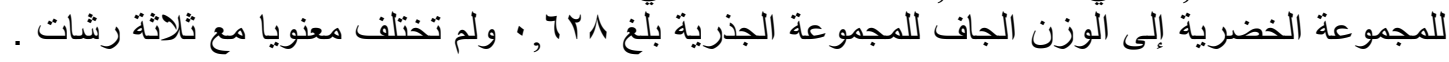




$$
\text { مجلة زر اعة الر افدين }
$$

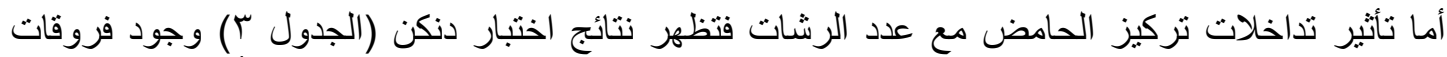

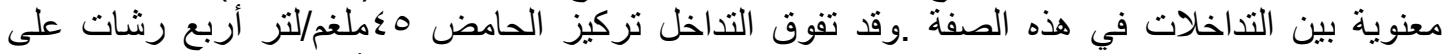

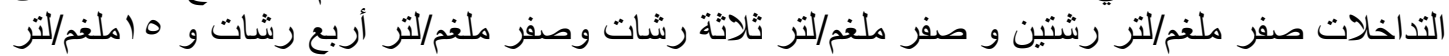

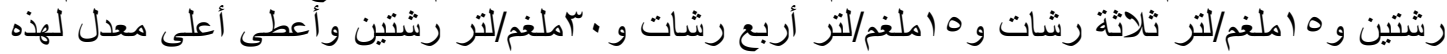

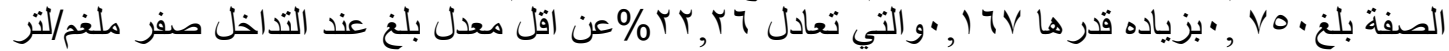

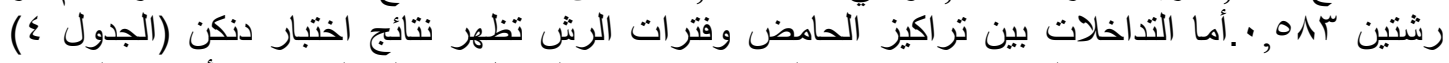

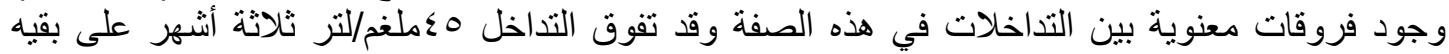

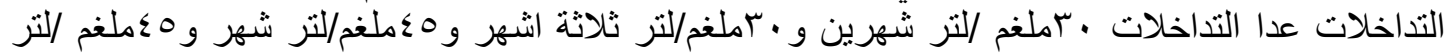

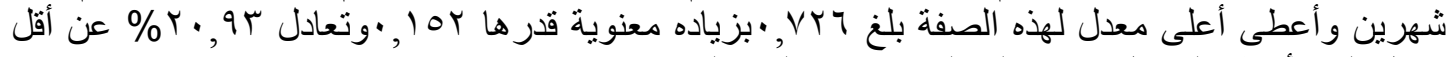

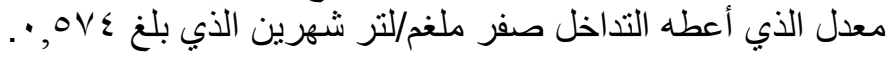

\title{
EFFECT GA3 OF CONCENTRATION OF NUMBER AND FOLIAR PERIODS ON SOME CHARACTERS GROWTH OF THE Quercus infectoria oliv SEEDLING IN THE NURSERY
}

Jyad A. Al-Ashoo

Hassan Nagmin

Forestry Dept. College of Agric. and Forestry , Mosul Univ. , Iraq

\begin{abstract}
The present study was conducted in the forestry department Nursery college of Agriculture summel. during the period of the end of Nov. 2004 to the end of Nov. 2005 to study the effect of the different concentration of GA3 Number and foliar period in growth and development of Quercus infectoria seedling. The study revealed that the concentration $45 \mathrm{my} / \mathrm{L}$ of GA3 was superiority in all concentrations and gave highest average of the characters length growth dry weight of shoots groups, dry weight Roots groups. Number of lateral roots and rate of shoots: Roots dry weight ratio [ $17.34 \mathrm{~cm} .2 .31 \mathrm{~g}, 3.25 \mathrm{~g}, 1.58$ lateral roots and 0.710$]$. The four spraying was superiority on the two and three spraying and gave highest average of characters length growth, dry weight shoots groups, dry weight roots group, number lateral roots and rate of shoots: roots dry weight ratio $[13.37 \mathrm{~cm}$, $1.88 \mathrm{~g}, 2.77 \mathrm{~g}, 1.39$ lateral root and 0.669]. Regarding foliar periods the three month period was superiority in all the periods and gave highest average in all characters [12.84 cm , 1.83g , 2.71g, 1.37 lateral roots and 0.665] .

$$
\begin{aligned}
& \text { المصادر } \\
& \text { أبو زيد، نصر الثحات ( •99 (1). الهرمونات النباتية و التطبيقات الزراعية /مؤسسة عز الدين للطباعة و }
\end{aligned}
$$

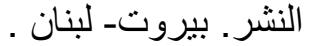

$$
\begin{aligned}
& \text { داود ، خالد محمد و زكي عبد الياس(، (99 (1).الطرق الإحصائية للأبحاث الزراعية، وزارة التعليم العالي }
\end{aligned}
$$

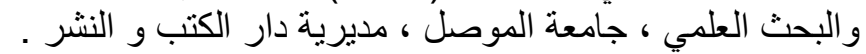

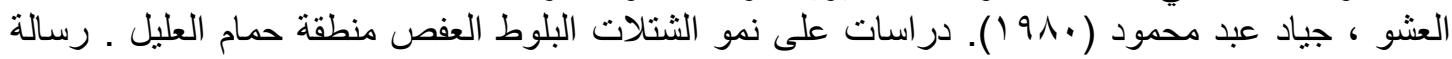

$$
\begin{aligned}
& \text { ماجستير ـ لكلية الزراعة و الغابات ـ جامعة الموصل. }
\end{aligned}
$$

Chopra , R.N. ,Nayar. S.L.\& I.C. Chopra(1986). Glossary of Indian Medicinal plant (Including the supplement). Council of scientific and Industria Research, New Delhi

Goswami , T.,T.C. sarma. ; D.N.Bordoloi and C.M. Samrah(1993). Response of sesbania aculeate, Baker to gibbereillic acid treatment for growth andbiomass yield.Bioresource Technology 44:8083. 


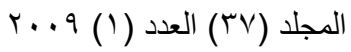

Harlow,W.M \& Ellwood .S. Harrar(1969). Text book of Dendrology. Hill Boot Co. , New York.

Herman, R.K. (1964). Importance of top-root ratio for survival Doglis-fire seedlings. Tree planters notes (64):7-11 (abstract).

Kathiresan , K. \& N. Rajendram (2002). Growth of many grove (Rhizophora apiculata) seedlings as influenced by GA3,Light and salinity. Revistade Bialoga Tropical, 50 ( 2 ) : 525 - 530 .

Mehrotra, M.\&V.S.Dadwal(1968). Study of the effect of gibberellic acid, Urea and Ralls traced on the growth of teak in the nursery - Enhancement of growth of seedling transplantable. Size in the same growth season-veritable possibility, Indian foresters . 706-713.

Racey , G.D. ; C.Gleram \& R.E. Hutchaon (1983). The practicality of top-root ratio in nursery stock characterization. For chron (abstract) (59):240-243 .

Shanmugavelu , K.G. (2000). Studies on the effect of plant growth regulators on cashew . Acta.Horti. (abstract) 50:241-248.

Singh , U.;C.K. Purohit \& T.S. sachdev (1984). Influence of phytohormones on growth and drymatter production in Madhuca latifolia, Indian for. 10 (9) :936943.

Vrinda, T.S \& Y.D. Singh (1999). Selection of tree species for energy plantation in arid, semi-arid area . 11-effect of fertilizers and gibberellin acid. Indian Forester . 125(8):807-817.

Wood, B.W. \& J.W. Hanover (1981). Accelerating the growth of black walnut seedling .Tree Planters' Notes 32(2) :35-38. 